\title{
Unlocking the Collections: getting comfortable with next-level access to museum minerals
}

\author{
Aaron J. Celestian ${ }^{1}$ \\ ${ }^{1}$ Natural History Museum of Los Angeles County (NHM)
}

April 28, 2020

A museum mineral collection is a vast repository of Earth and planetary materials. It is a resource for researchers looking to gain access to the rarest minerals and gems, and those that are looking for intricate details in species variation. Some researchers need access to common minerals, but don't have the means to acquire specimens themselves. More importantly, in my opinion, a museum mineral collection can be used to inspire wonder to our visitors, inform the public of current issues in a safe and comfortable space, shape their world view if they trust us, or just allow them to appreciate Nature's creations. The collections need to be accessible at all levels.

When it comes to unlocking the museum's mineral collection, what we are talking about is accessibility, and are there only two groups of people to which this mainly concerns. They are the professional researchers and the general public.

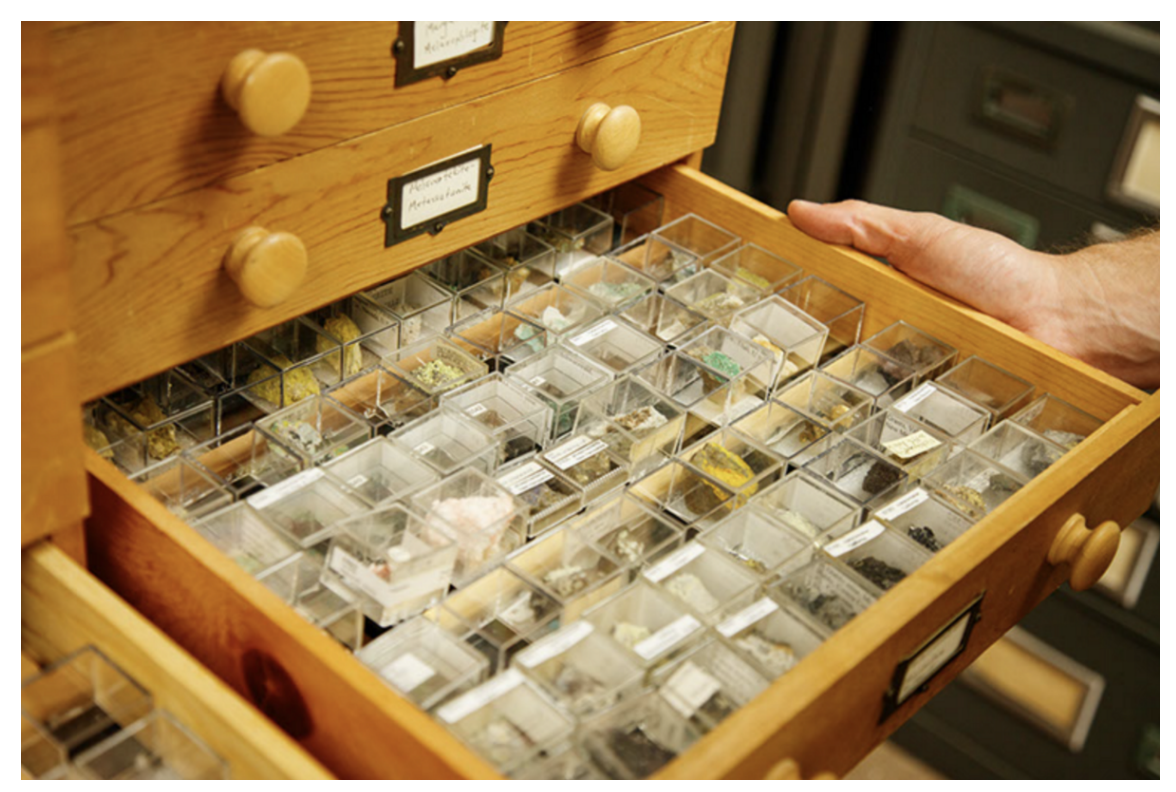

Figure 1: A researcher accessing parts of the mineral collection at NHMLA. Our collection can be search at https://colections.nhm.org/mineral-sciences/ 
Researchers. These are people who can gain direct access to the collections, either by looking through the stacks of minerals housed at the museum, or by borrowing specimens that can be taken off-site (or we mail it to them) to be investigated elsewhere. These researchers go behind the scenes, and nearly all of these research projects are academic and non-profit in scope. If researchers do not use the museum collection, then the research collection is doomed as the overseeing governing bodies may lose trust in the usefulness of the collection. So what are the most important minerals that the mineralogist/geochemist/scientist need?

Public. This group is limited to viewing selected specimens that the museum deems vital for the exhibit. The level of scientific information that is conveyed to the public is often limited in scope (or out of date soon after exhibit installation), and the degree of information given to illustrate the importance of the collection is often omitted. In general, this group of people cannot physically access the collection, nor can they see the vast collections that museums house. A critical issue to address is that they don't understand why we need collections in the first place.

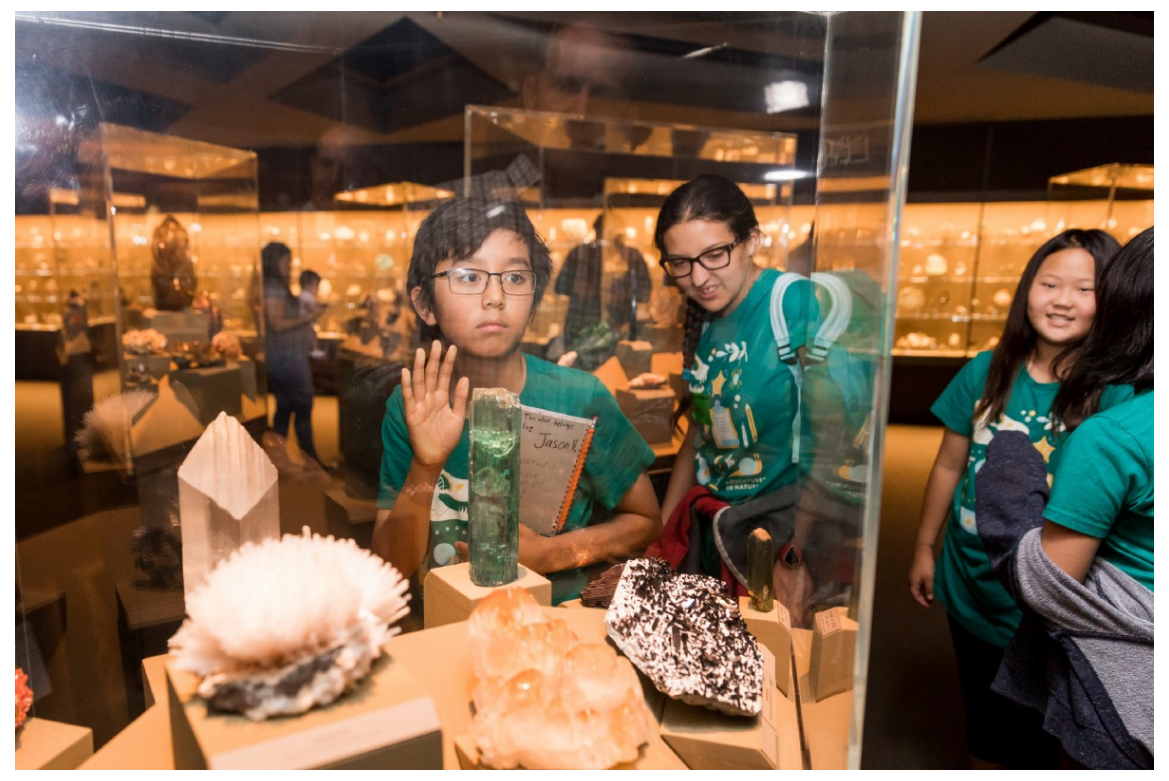

Figure 2: A visitor looks as if they want access to this part of the mineral collection.

So two aspects need addressing regarding accessibility in the future:

1) How to obtain the most scientifically significant materials for future researchers, and 2) how to make the museum's collection more intellectually accessible to its public community.

\section{Part One: The Researchers' Needs}

Standards. Right now, scientists use trusted standards to compare data collection and analysis techniques, as well as to calibrate their instruments. Having calibrated instruments using agreed-upon standards also gives confidence that the data obtained from their experiments will all be valid and comparable. The National Institute of Standards and Technology is an excellent place to go, but few people can afford to buy these standards. There are other places to go for materials, the Clay Mineral Society has a good set of clay standards, the United States Geological Survey has their own set of standards (e.g., rocks), and even university laboratories sell their internal standards to outside users. There are also some generally agreed upon standards that are not housed at any one institution, such as the forsterite from San Carlos Indian 
Reservation. In general, standards are expensive to buy, and they are in limited supply. In practice, there are not enough standards for every situation, and sometimes you just need the same material another researcher used in their past work so you can compare numbers.

If the role of the museum is to be a repository of materials that contain a detailed analytical history, and as researchers continue to contribute data on these materials, then the museum collection effectively becomes a free to use standard, becoming more valuable to researchers in the process. But it only works well if people share.

Get Access Now. The museum also houses otherwise inaccessible material. For example, maybe a researcher wants to compare minerals that are included in diamonds from South Africa to those from Brazil. It may be possible for that researcher to: 1) Visit these remote places, somehow gain access to the mines, broker a deal to take the diamonds (at a price), get through customs, and hope that the minerals obtained possess interesting inclusions. Or, 2) go to a museum, search the curated diamond collection for South Africa and Brazil specimens, select the mines of interest, get preliminary data on all potential minerals to ensure usability, and borrow specimens for further investigation. The second option is far simpler and more efficient, and obviously, this scenario can be applied to other mineral research projects. I also realize that not everyone can afford to go to a museum, and we are trying different things to solve this problem. Of course there is value in the first option, but it is less accessible option to most people.

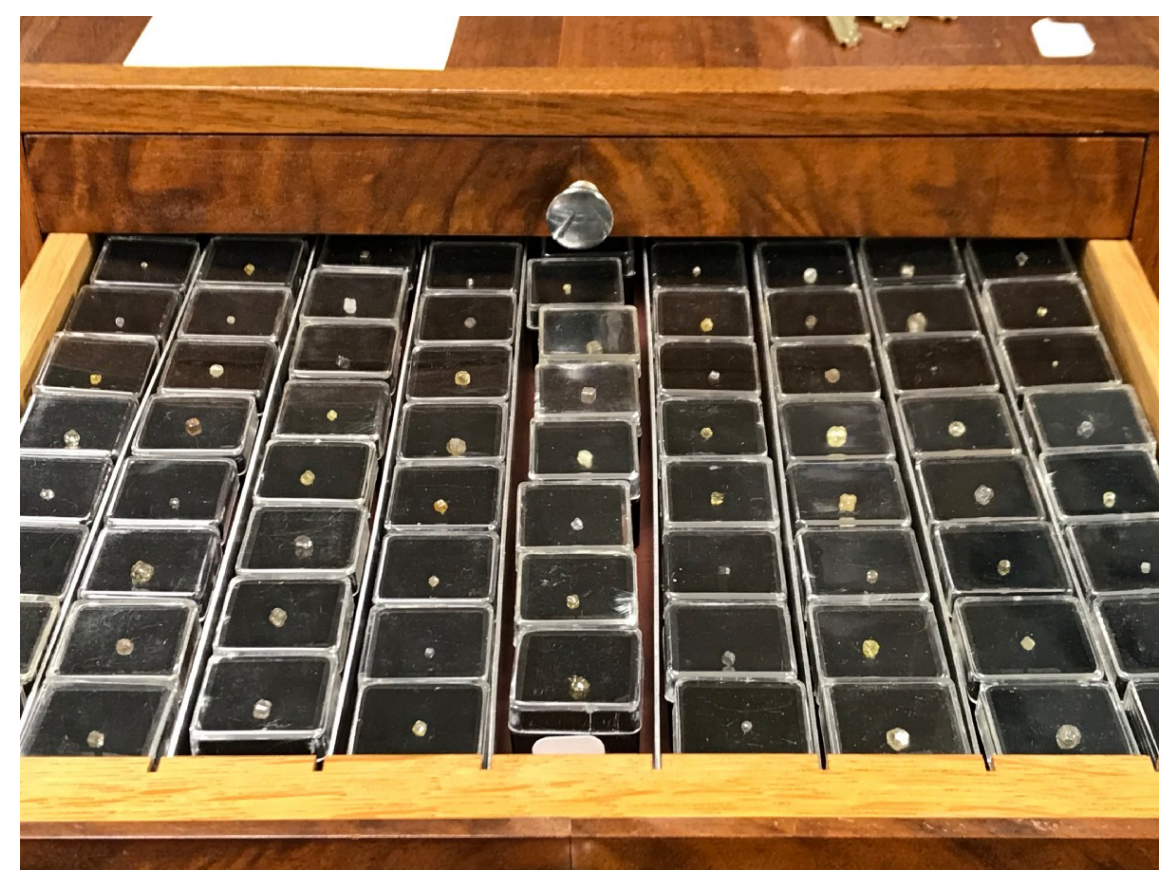

Figure 3: An example of the diamond reference drawers at NHMLA. Each one of these small plastic boxes holds a single diamond of known origin.

Predicting the Future. It is impossible for a museum curator to predict what minerals of interest will be needed for the ever-advancing sciences in the future, so we curators hoard everything in anticipation that something might be needed. Who wants to deaccession something that might have potential unlocked secrets? I don't want to be that person, but it is something we have to do to keep the museum clean, 
up-to-date, and have room to grow. One predictable thing is the need to study the past; building upon past research rather than starting from scratch. By reevaluating old studies and previously analyzed materials with new analytical techniques and hypotheses, we would be adding to the total accumulated wealth of knowledge - seems obvious. Instead, what normally happens is that a researcher's minerals used in those scientific publications get disposed of when they move to another institution, or when they retire.

Most universities do not have a good track record of preserving scientific materials (or even university museums). As a graduate student, I remember moving a retired professors research specimens into the "hazardous waste" bins to clear out space for a new incoming professor. At the time, I felt like I was throwing away history, but none of the bottles were labeled with information that I could decipher (just a bunch of notebook numbers, odd looking codes, and abbreviations). And when I moved from my previous institution to NHMLA, I'm sure that any minerals I left behind were also disposed of as waste.

A museum can be the house for those scientifically valuable minerals because, by its strategic framework, it has the staff and resources to catalog, house, conserve, loan, and perform research on those minerals. But museums need help in building that repository, and that help needs to come from the scientific community. Researchers have to trust that a museum will care for, and make available, these materials forever.

So what is the hesitation?

Why are mineralogists not donating their studied, but no longer being used, specimens to museums?

A glimpse of this may not be all that different than a study published in Nature of this year (2019) showing why researchers do not share 3D scans of fossils. I can see similarities to the mineral world, and the figure below would be considered generous. In my 3.5 years at NHMLA (I started in 2016), there hasn't been a single sample of material donated to our collection from a published research project. Before I arrived at the museum I never submitted material for their collection, but now I do. I didn't donate my specimens to a museum because I didn't think it was important. None of my colleagues told me that it would be a good idea to deposit my studied materials into a museum, and in fact, it was never even discussed! I didn't think a museum would consider them valuable enough, or be of general interest to other researchers. I was wrong.

Aggregating collection information. This is a useful way to share collection data from multiple institutions in a centralized database, and mineral databases are far behind our biological sciences colleagues. With iDigBio and GBIF, they help educate best practices for digitization, provide infrastructure for database management and a place to deposit data, and promote usage. IDigBio, has researcher highlights, best practices on collecting and sharing data, education \& outreach working groups, K-12 integration, community science initiatives, and much more. The biological databases are good examples, as they work very well.

There needs to be an open and accessible centralized repository of information that has data on where specimens are housed, and scientific data on those specimens, plus all the needed education to keep mineral collecting and the related sciences moving forward. I understand that open databases can be abused, but an active user community can serve as an overseeing body to get things mostly accurate. Examples of some databases where geologists can contribute data are Earthchem, Crystallographic Open Database, Pangea, but they typically only house data, and are not user-friendly. 


\section{WHO SHARES 3D SCANS?}

Nature analysed the 200 most popular* palaeontology papers across 2017 and 2018. Of 122 that described 3D objects, just under half -59 papers collected 3D imaging data. But only $31 \%$ of these shared that data online.
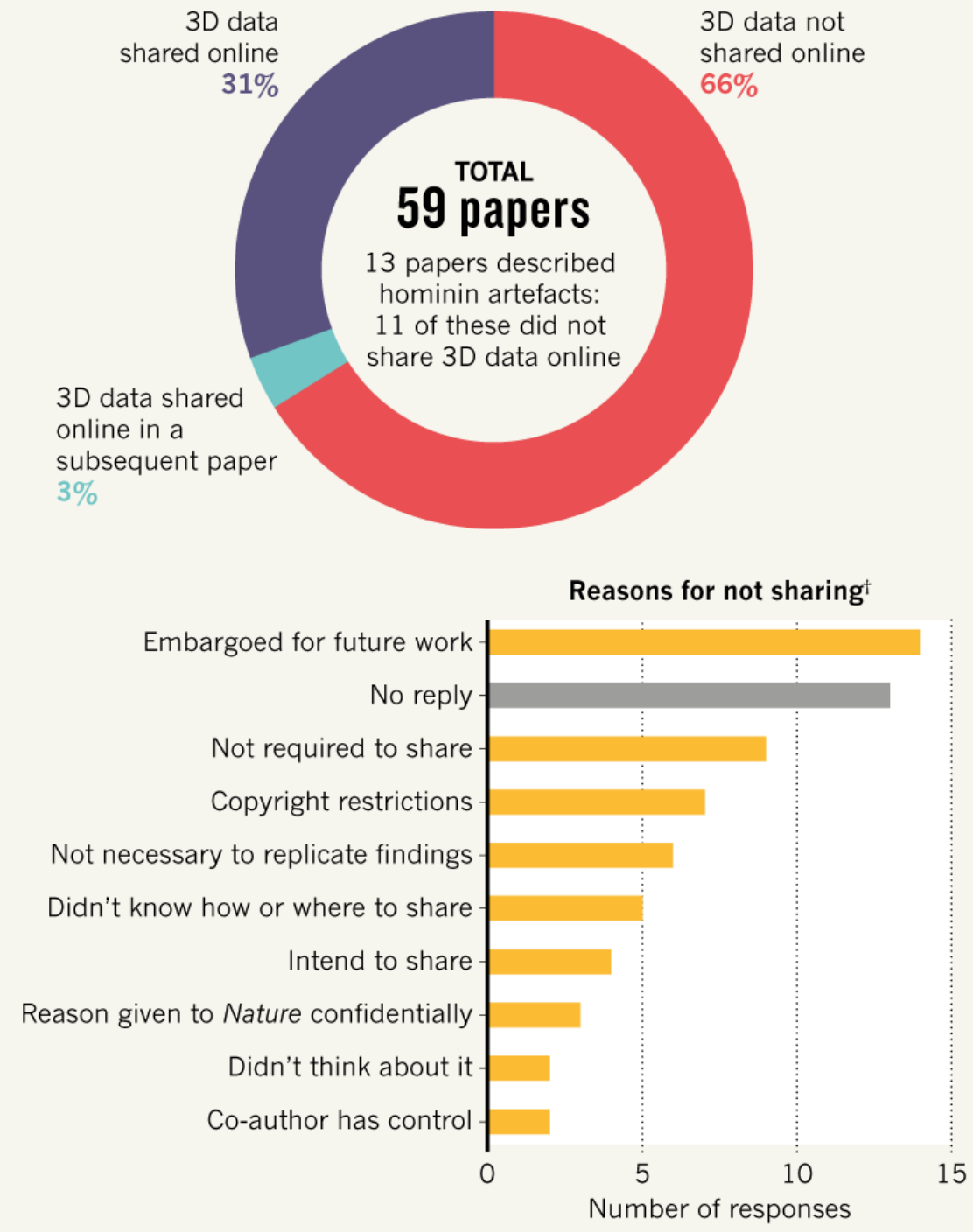

* By Altmetric Attention Score, which is one way of measuring attention to research articles in news and social media. † Some authors gave multiple responses.

onature

Figure 4: This study can be used as a barometer as to why researchers do not share information, and why they might not share specimens with museums. It seems most researchers just don't want to share. But why? Fear of contradictory analyses, competition among research groups, lack of organization of data-tomineral, ... ?

\section{How A Researcher Can Increase Their Impact}

- Donate your no longer being used, but published, specimens. Please include a DOI (digital object identifier) and a photo if they are available. 


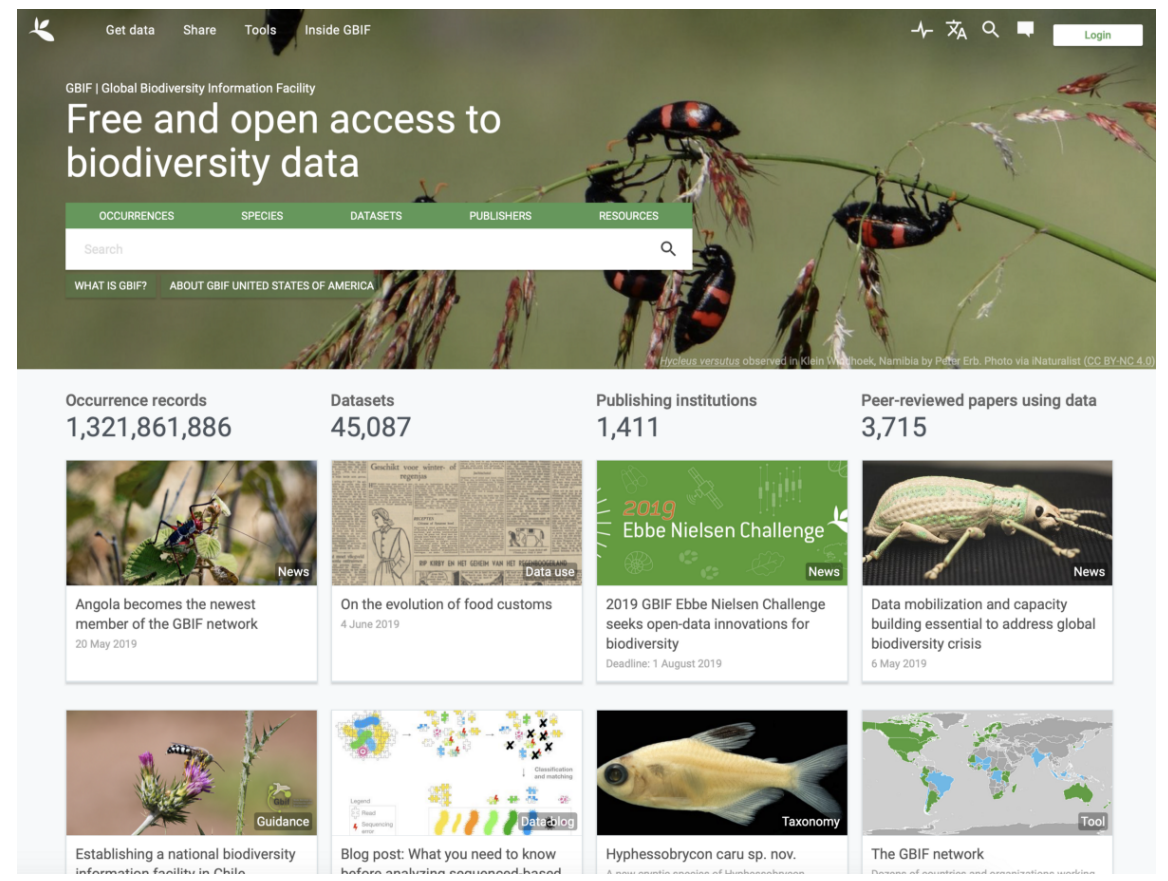

Figure 5: The home page of GBIF, global biodiversity information facility, has a pleasing and easily accessible format.

- Donate characterized, but unpublished specimens. Do you have electron microprobe data, XRF, Raman, FTIR, ICP, XRD, or other? We can include that data in our database along with a photo. Plus, you can also write a short data report and publish it on a free pre-print server (like ChemRxiv, or Authorea which is my personal fav), so you have a DOI and people can reference your work.

- Ask for materials to perform research on, and if published, submit the data to a repository or back to the museum.

- Credit the museum for all work done on a museum object, this helps bring awareness to the museum's strategic goals for making the collection accessible.

- Apply to a museum collection fellowships/grants to help with travel costs.

\section{Help Your Museum Through ...}

- Community engagement, go to museum events!

- Go to classes/workshops, and suggest other workshops.

- Going on or leading local field trips, they can be fun!

- Not sure what to do? Just email your favorite museum mineral curator to discuss options.

\section{Part Two: Public Trust \& Education}

Museums are among the most trusted sources of information to the public. Just google "Do people trust museums?" and "Do people trust universities?" and you will see a stark contrast of results. People trust Google above all else, so you know these results speak the truth. Sarcasm aside, keeping that trust, and also bringing the collection to the public is constant work.

Each year, hundreds of thousands of people visit the museum I work (NHMLA). They come to see things that they can't see, or experience, anywhere else. They also trust that the museum is a vetted source of knowledge 


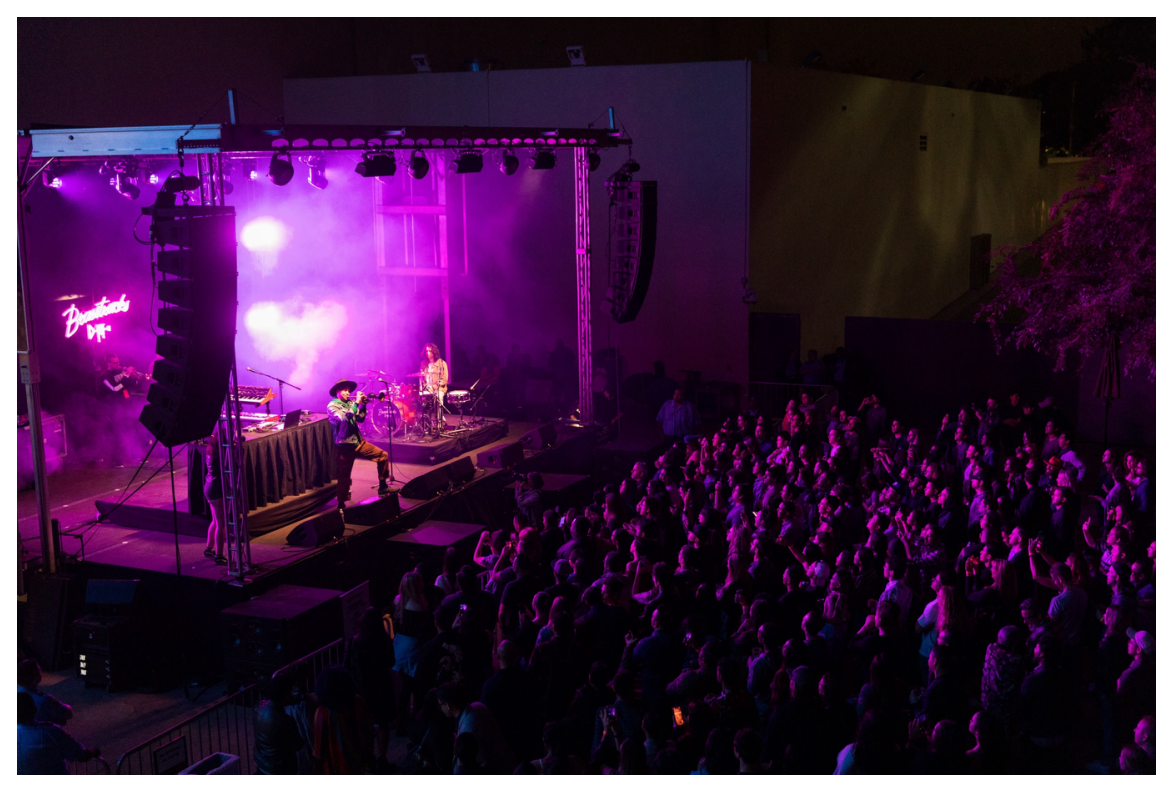

Figure 6: Typical First Fridays concert at NHMLA. Can you see me in the crowd? First Fridays has food, drinks, scientists, discussion panels, tours, concerts, and everything else to have fun and make people feel comfortable. All the while being as educational as possible.

and education. The community also feels safe in sharing ideas and opinions at a museum. There is space to have fun and share new experiences: First Fridays, Bug Fair, Dino Fest, Summer Nights, playful gardens, traveling exhibits, weddings, proms, nights at the museum, summer camps, and many other activities that make a museum a magical place.

So how can we continue to promote public trust, interest, and education using a museum's mineral collection? The physical objects in the collections will likely stay protected in their cabinets for a while, but data doesn't have to be. We should be able to trust our community scientists and professional scientists to help find cataloging mistakes, help organize images \& data, and even share information (many museums are already doing this) and documents to be a part of the collection. For example, is a mineral club writing newsletters about the geology of a local mine? That should be included in the museum's database and crossreferenced with the specimens in the collection! The museum can collaborate with the broader community like universities (e.g., RRUFF, do they still add things to the database?) and non-profits (e.g., Mindat), to make finding trusted information as easy as a google search.

\section{Things That A Person In The Community Can Do To Help}

Museums are for the community, and the community needs the museums. We need to work together.

- Donate your collection when you are no longer using it. The vast majority of mineral specimens in our museum are by donation, and this is the only way we can grow. Please donate. It's easy, and you get tax breaks.

- Credit the museum for all work done with museum data, this helps bring awareness to the museum's strategic goals for making the collection accessible.

Help Your Museum Through ... 

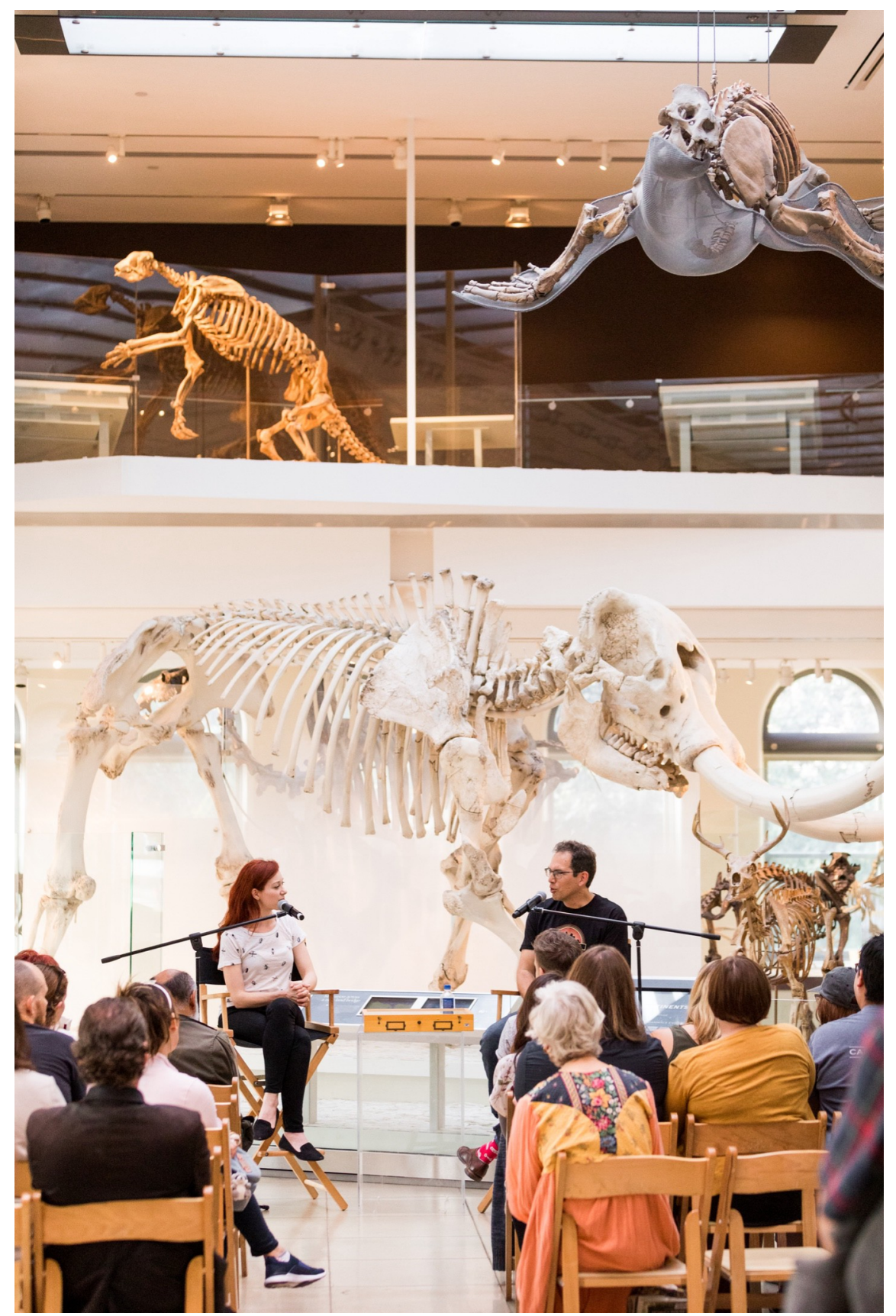

Figure 7: I The community is welcome at NHMLA panel discussions.

- Community engagement, and a shout out to the Mineralogical Society for Southern California for all their work with the community!

- Rock and mineral club trips to the museum

- Local field trips to collecting spots. Bring a curator along, they don't know everything, and they like to learn too! 


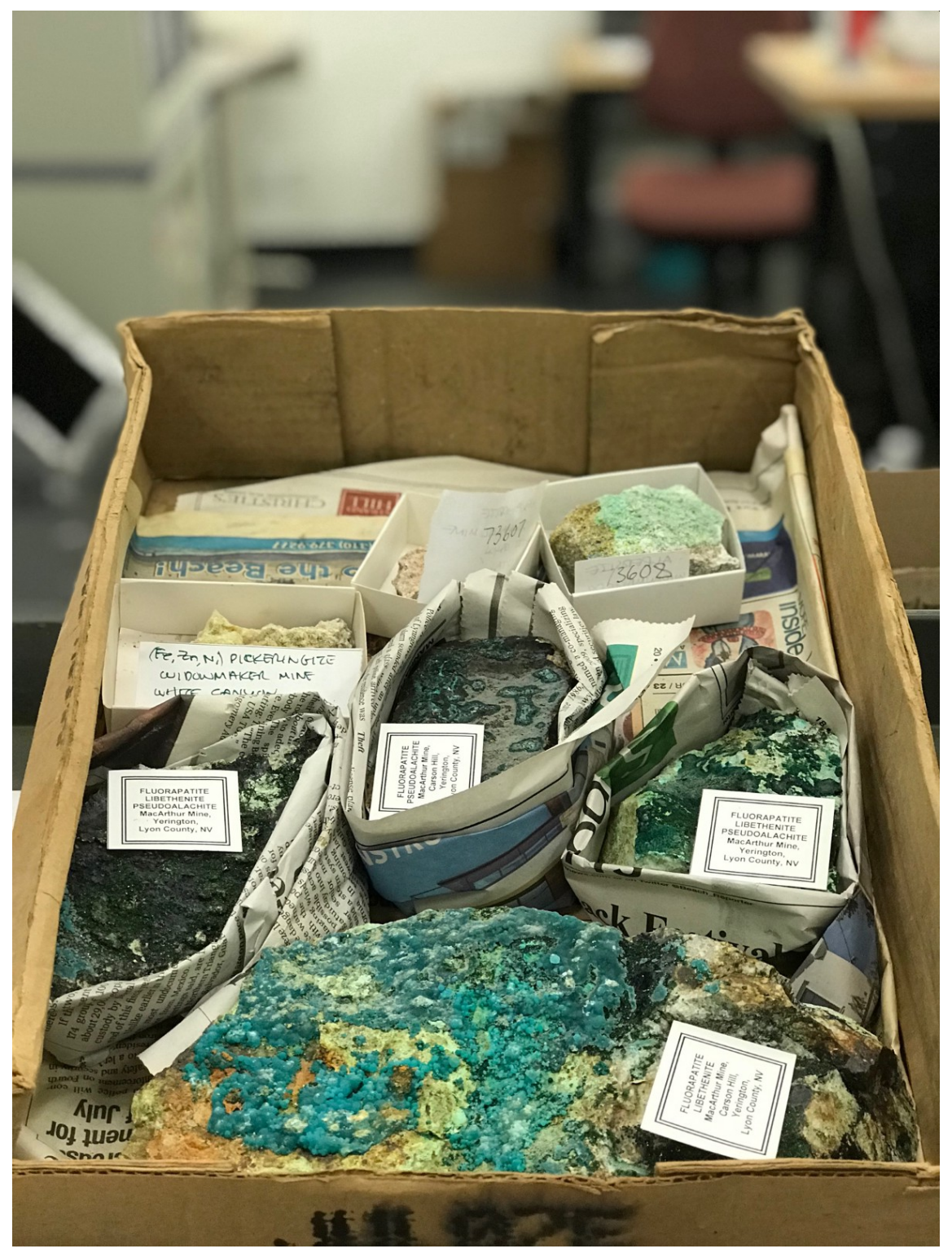

Figure 8: Typical type of donation we receive. This is representative material from the MacArthur Mine in Nevada. These minerals will be cataloged, photographed, and then immediately available for search on our database.

The Importance of Collections. A mineral collection provides a consolidated resource for research and education. Even when field sites become mined out, built over because of construction projects, or altered because of environmental changes, the collections will endure. But the collection can be used to engage people on many levels including education programming, summer camps, accessible public lectures, public programs, volunteer programs, docent programs, audio tours, exhibits accessible to the impaired, co-created exhibitions, social media, augmented reality, expeditions, and traveling exhibits. In addition, online content and interactions are getting richer, more accessible, and easier to implement all the time. Each one of the listed items above would be a blog post on its own about how mineral collections can be integrated into those outreach aspects. But in the end, a museum can do all/some of these, or none of these. There are a 
considerable number of ways to engage the public in this way, even showing them things that they didn't know they wanted, and having some members of the public be a part of the museum collection/exhibition process will instill them into the community as ambassadors and champions of the collection. What matters is that the museum listens to what the public wants and acts accordingly to deliver trusted, factual, and digestible content. The collections are the scientific and educational resource of undeniable facts.

In the end, building on the trusted relationship with researchers and the community is probably how a museum mineral collection will continue to be used, accessed, and grow for the next 100 years.

\section{Further Readings:}

I will update this with articles that I find useful and interesting.

Be better at organizing your data and samples. https : //www . asm .org/Articles/2019/February/SparkingJoy-with-Research-Organizing-Your-Data

A museum opening its 'stores' for greater collections access. https://advisor.museumsandheritage.com/ features/lapworth-museum-geology-factoring-public-access-stores-part-major-redevelopment/

A sense of history: making museum collections acessible for all. https://nmsteachingmuseum. wordpress . com/2014/10/29/a-sense-of-history-making-museum-collections-accessible-for-all/ 